\title{
Conflicto social, ambientalización y crisis política: judicialización en la cuenca Matanza-Riachuelo, Argentina
}

\section{Social conflict, environmentalization and political crisis: judicialization at the Matanza- Riachuelo basin, Argentina}

AndrÉs SCHARAger*

\begin{abstract}
This paper examines the social and political factors that led to the judicialization of the environmental conditions of the Matanza-Riachuelo basin, a highly polluted territory in Buenos Aires that in 2006 became the object of an unprecedented problematization. Specifically, three factors will be analysed: the creation of an environmental field and the generation of a series of environmental conflicts; the environmentalization of social demands along the Riachuelo river and the emergence of a basin perspective; and the Supreme Court's search for a political relaunch in response to a crisis of legitimacy.
\end{abstract}

Keywords: environmental conflicts, judicialization, Matanza-Riachuelo basin.

\section{Resumen}

En este escrito se examinan las condiciones sociales y políticas que condujeron a la judicialización de la situación ambiental de la cuenca Matanza-Riachuelo, un territorio altamente contaminado en el Área Metropolitana de Buenos Aires, que en 2006 se volvió objeto de una renovada e inédita problematización. En particular, se analizarán tres factores: la conformación de un campo ambiental y la generación de una ola de conflictos socioambientales, la ambientalización de las demandas en el Riachuelo y la construcción de una perspectiva de cuenca, así como la búsqueda de relanzamiento político de la Corte Suprema como respuesta a una crisis de legitimidad.

Palabras clave: conflictos ambientales, judicialización, cuenca Matanza-Riachuelo.

* Instituto de Altos Estudios Sociales-Universidad Nacional de San Martín/Consejo Nacional de Investigaciones Científicas y Técnicas, correo-e: andres.scharager@gmail.com 


\section{Introducción}

La cuenca Matanza-Riachuelo constituye una de las principales postales de la vulnerabilidad social y el riesgo ambiental en Buenos Aires. Con $2238 \mathrm{~km}^{2}$ de superficie que atraviesan 14 municipios, este territorio abarca gran parte del Área Metropolitana y conforma -junto con sus afluentesuna cuenca hidrográfica con más de ocho millones de habitantes. Mataderos, curtiembres y saladeros se volvieron parte de su paisaje desde principios del siglo XIX, y con ellos comenzaron a acumularse contaminantes de manera sostenida hasta la actualidad. Pero la ausencia de políticas de control y planificación sobre los usos de la tierra y los recursos hídricos condujeron a que, en ese lapso, las fuentes de polución de origen industrial fuesen apenas uno de sus tantos problemas. Con el tiempo, se sumaron también aguas pluviales que arrastran secreciones de residuos sólidos urbanos, fluidos cloacales vertidos sin tratamiento, basurales a cielo abierto en las orillas y metales pesados peligrosamente sedimentados en el lecho. ${ }^{1}$

Aunque cuenta con problemas tan estructurales como urgentes, la ausencia de soluciones ha perfilado la situación de la cuenca a lo largo de su historia. En 1811, en plena consolidación del gobierno independizado de la corona espańola, se dictaminó por primera vez la necesidad de limpiar el río ante la contaminación provocada por las industrias alimenticias. Sin embargo, esta política fue incumplida, como tantas otras que le siguieron, las cuales van desde decretos como el de 1822, que prohibió la instalación de nuevas curtiembres y mataderos, hasta leyes como la de 1913, que ordenó obras de rectificación, iniciadas pero nunca terminadas (Rocha, 2005).

A partir de sucesivos hitos como estos, el Riachuelo se hundió poco a poco en el desgobierno, su destino se ató al solapamiento de acciones descoordinadas y carentes de previsión y, así, el territorio estuvo lejos de volverse objeto de atención institucional sostenida. En efecto, tan temprano como 1871, el diario La Nación sostenía:

El lecho del Riachuelo es una inmensa capa de materias en putrefacción. Su corriente no tiene ni el color del agua. Unas veces sangrienta, otras verde y espesa, parece un

${ }^{1}$ Esta sumatoria de factores ha hecho que, paulatinamente, el Riachuelo se convierta en uno de los ríos más contaminados del mundo (Di Paola et al., 2009), mas no el único caso de su tipo; por lo contrario, la acelerada urbanización acontecida desde la segunda mitad del siglo XX en América Latina -particularmente en los países que atravesaron procesos de industrialización intensa-conllevó un incremento de la contaminación en las ciudades y, en especial, una estrecha asociación geográfica entre las desigualdades sociales y el riesgo ambiental (Harvey, 1996; Jordán et al., 2017; Clichevsky, 2002). En este contexto, han proliferado los conflictos urbano-ambientales en metrópolis como México (Schteingart, 1987; Espinosa, 2015), Río de Janeiro (Fuks, 1998), Bogotá (Quimbayo, 2014), Santiago de Chile (Aliste y Stamm, 2016) y Medellín (Palmett, 2016). 
torrente de pus que escapa a raudales de la herida abierta en el seno gangrenado de la tierra. Un foco tal de infección puede ser causa de todos los flagelos, el cólera y la fiebre. ¿Hasta cuándo inspiraremos el aliento y beberemos la podredumbre de este gran cadáver tendido a espaldas de nuestra ciudad? (Rocha, 2005).

Si al calor de la industrialización del siglo XX el Riachuelo se convirtió en un símbolo de la degradación ambiental urbana, el fallido proyecto de saneamiento presentado durante el gobierno de Carlos Menem (19891999) lo apuntalaría como emblema de la desidia y la corrupción.

En 1993, la secretaria de Recursos Naturales y Ambiente Humano de la nación, María Julia Alsogaray, anunció un plan para sanear la cuenca del río en mil días; aseguró que al cabo de ese plazo estaría "descontaminado" y sería posible "tirarse a nadar" allí. El propio presidente, Carlos Menem, haría eco de la promesa al afirmar: "en 1995 vamos a ir allí a pasear en barco, a tomar mate, a bañarnos y a pescar" (Clarín, 2006).

Pero hacia 2002, los 250 millones de dólares que había otorgado el Banco Interamericano de Desarrollo para estos fines habían sido reasignados para el financiamiento de planes sociales y cuestionados servicios de consultoría (Clarín, 2006; Maciel y Groisman, 2003). El "plan de los mil días" no tardó en convertirse en uno de los mayores ejemplos del incumplimiento y el abandono del Riachuelo, mientras que Alsogaray se volvería un ícono de la malversación de fondos y los escándalos políticos de la época.

Con este fracasado intento del menemismo sobre sus espaldas, la Corte Suprema de Justicia de la Nación ${ }^{2}$-tribunal de mayor jerarquía constitucional en la Argentina- comenzó a escribir una nueva (y acaso la más trascendente) página en la historia del Riachuelo en 2006, pues declaró su competencia originaria ante una denuncia presentada dos años antes por un grupo de vecinos y trabajadores de la salud del municipio bonaerense de Avellaneda, quienes encabezados por la ciudadana Beatriz Mendoza (de quien devino el término causa Mendoza, con el cual se hace habitualmente referencia a este proceso), le exigían al Estado nacional, a la Provincia de Buenos Aires, a la Ciudad de Buenos Aires y a 44 empresas, una reparación por los daños y perjuicios causados por la contaminación del río.

$\mathrm{Al}$ asumir la conducción de este proceso $-\mathrm{y}$ fundamentalmente cuando dictó sentencia definitiva en 2008-, el máximo tribunal trascendió las expectativas de los denunciantes y conminó a los tres gobiernos a presentar un plan integral de saneamiento para la totalidad de la cuenca. ${ }^{3} \mathrm{Si}$ bien

\footnotetext{
${ }^{2}$ En adelante, Corte Suprema.

${ }^{3}$ Merece subrayarse que la cuenca Matanza-Riachuelo comprende un territorio bajo tres jurisdicciones diferentes: la ciudad de Buenos Aires - autónoma-, la provincia de Buenos Aires y la Nación. Esta tripartición, históricamente, condujo a solapamientos y vacíos institucionales, que en su conjunto dificultaron las capacidades de articulación, la planificación política y el ordenamiento del suelo. A raíz de ello, la mencionada sentencia judicial condujo a la creación de un organismo tripartito -Autoridad
} 
dicho tribunal dejó pendiente la definición de la reparación del daño ambiental colectivo y se declaró incompetente en lo referido a los reclamos individuales, determinó como objetivos la mejora de la calidad de vida de los habitantes, la recomposición del ambiente en la cuenca en todos sus componentes (agua, aire y suelos) y la prevención de daños con suficiente y razonable grado de predicción (Corte Suprema de Justicia de la Nación, 2008).

A partir de su decisión -y de su disposición explícita a determinar responsabilidades, plazos de cumplimiento y lineamientos-, la Corte Suprema captaba el conflicto del Riachuelo y lo trasladaba compulsivamente al campo del derecho, sometiéndolo a los procedimientos del sistema judicial y a las reglas jurídicas (Azuela, 2006). Por otro lado, se colocaba en un rol de estructuradora y organizadora de un proceso crecientemente complejo que buscaba introducir al orden de lo político un área geográfica que apenas estaba recortada y delimitada en términos sociales y estatales.

Mucha agua ha corrido bajo el puente entre el inicio de este proceso judicial y la actualidad, tanto en un sentido institucional como en materia de resultados alcanzados. Pero no es el propósito de estas páginas colocar bajo escrutinio el derrotero de la causa Mendoza en los últimos años, lo cual ha sido foco de pormenorizados análisis (Nápoli y García, 2011; Fundación Ambiente y Recursos Naturales et al., 2017); por lo contrario, el interés está puesto en los hitos de la historia reciente que han dado lugar a la apertura de esta nueva etapa.

Lejos de asumir la renovada problematización estatal de la situación del Riachuelo como producto de cambios en la moralidad -que volvería socialmente inaceptable la contaminación- o en la eficiencia del Estado argentino -que sólo requeriría de una decisión política y transformaciones burocráticas para la puesta en marcha de un plan integral- se apuntará aquí a examinar las condiciones de posibilidad que habilitaron la inédita centralidad de la cuestión en la agenda pública. En otras palabras, no se lo asumirá como el producto de una decisión contingente de la Corte Suprema, sino que se analizarán los factores sociales y políticos que dieron lugar a la judicialización de la situación ambiental de la cuenca y su reterritorialización (Mançano, 2012).

Con este objetivo se examinarán el surgimiento y desplazamiento de la cuestión del Riachuelo entendida como problema público: un asunto de preocupación social que adquirió diversas formas de atención y tratamiento por parte de las agencias estatales. Para responder cómo adquirió este estatus se debe suspender su carácter natural o evidente y observar

de Cuenca Matanza-Riachuelo- que cuenta con plena potestad sobre el territorio en lo que se refiere a tareas de saneamiento. 
los modos y las operaciones sociales a partir de las cuales se produjo su objetividad práctica (Guerrero-Bernal et al., 2018). En otras palabras: aquí se analizará cómo se volvió un asunto de interés político, social y judicial; cómo se generaron las condiciones de posibilidad para su captura por parte de la justicia y la esfera del derecho.

Investigadores como Hilgartner y Bosk (1988) y Cobb et al. (1976) advierten que la atención pública es un recurso escaso y que el ingreso de una cuestión a la agenda pública depende de operaciones cognitivas y políticas; este artículo mostrará cómo se generaron y cuáles fueron los principales movimientos a partir de los que el tratamiento social y estatal de la contaminación de la cuenca se transformó.

De acuerdo con Alfie (2013), podría sostenerse que esta transformación redundó en la conformación de una nueva gobernanza ambiental, pues operó como puntapié para la creación de una autoridad de cuenca y propició que las instituciones estatales recortasen dicho territorio como una escala de intervención en sí misma. El fallo habilitó un campo de deliberación sin precedentes; esto es, constituyó un "giro deliberativo" (Alfie, 2013: 82) se ha caracterizado por una impronta judicial.

Investigaciones como las de Güiza et al. (2015) han analizado la judicialización de distintos conflictos ambientales en América Latina, examinando los efectos que tiene en su estructuración el ingreso de actores e instituciones del campo jurídico (Bourdieu, 1987). Autores como Melé (2006) y Azuela y Cosacov (2013) han señalado los impactos simbólicos que puede tener el traslado de los conflictos a los tribunales, desde cambios en sus modos de encuadramiento hasta su inserción en distintas cadenas discursivas.

Por este motivo, destacan la necesidad de hacer foco en su productividad con el fin de atender sus consecuencias duraderas y de largo alcance. No obstante, es preciso examinar de qué forma los conflictos se vuelven foco de atención judicial, y cómo la cuestión ambiental acaba por ingresar en la agenda pública. En otras palabras, se debe analizar de qué modo, en casos como el del Riachuelo, los distintos actores sociales y políticos reconfiguran su tratamiento público y cómo el nuevo estatus del problema es captado y tratado judicialmente.

\section{Metodología}

Este artículo se inscribe en una investigación de mayor alcance acerca de la relación entre la judicialización, la ejecución de políticas estatales y el conflicto social (Scharager, 2019). Se ha optado por un diseńo de investigación cualitativo que se asienta en la técnica de análisis documental y bibliográfico y se ciñe al periodo 1994-2008. Este último año es en el que 
la Corte Suprema dictó sentencia definitiva y se trata, por ende, del punto de llegada del análisis de estas páginas, que apunta a explicar precisamente el porqué de dicho fallo, entendido como puntapié de un nuevo modo de tratamiento público del problema del Riachuelo.

El año 1994, mientras tanto, se establece como momento de inicio de este estudio debido a que fue en ese entonces que -según se verá- se produjeron transformaciones que encuadraron localmente y en un plano institucional el surgimiento de la nueva cuestión ambiental.

El trabajo se sostiene en fuentes secundarias que consisten mayoritariamente en documentos institucionales (fallos judiciales, legislación, informes), si bien también es de relevancia el análisis de libros y artículos científicos. Asimismo, a fin de contextualizar el objeto de estudio se examinaron archivos de prensa gráfica (diario La Nación) por medio de motores de búsqueda web. En todos los casos se realizó un análisis inductivo de contenido que, específicamente, apuntó a una revisión selectiva de información (Andreu, 2002) con el auxilio del software Atlas.ti (QDA, 2017) para identificar elementos explicativos del problema en cuestión; a partir de ellos se examinaron cada uno de los factores identificados como relevantes para el esclarecimiento de la transformación de la situación ambiental de la cuenca en un problema judicial.

Estos factores -en función de los cuales se estructura este trabajo- se dividieron en tres dimensiones de análisis, que no se corresponden per se con secuencias temporales: en primer lugar, la conformación de la cuestión ambiental a nivel global y la manera en que, a nivel local, comenzó a proliferar un sinnúmero de conflictos ambientales que colocaron la problemática sobre la mesa a modo de demandas sociales. En segundo lugar, la emergencia de una renovada problematización de la situación en el Riachuelo en clave ambiental, y cómo un conjunto de organismos estatales y actores con saberes expertos dieron pie a una articulación política y cognitiva de la situación desde una perspectiva integral sobre la cuenca. Finalmente, el contexto político inmediato que -según se argumentarácondujo a la decisión de la Corte Suprema de asumir la conducción de la causa Riachuelo. Se destacan en él la crisis nacional desatada en 2001 y la deslegitimación social del Poder Judicial.

Los factores que conducen a la transformación en los modos de tratamiento de un problema público son, según Weber (2012), potencialmente infinitos; para alcanzar una explicación causal se requiere una labor de imputación o selección de determinados elementos que indefectiblemente irá en detrimento de otros recortes posibles. Como afirma Rossi, "puesto que la totalidad de las relaciones de causa y efecto de las que depende la ocurrencia de un fenómeno es conceptualmente inagotable, el campo de 
investigación dentro del cual se mueve la investigación debe ser delimitado sobre la base de una selección" (2012: 23).

El hallazgo de una causación adecuada (en oposición a una causación accidental) siempre será, en esta clave, el producto de un proceso hipotético que a priori se sostiene en relaciones de valor subjetivas. Este artículo propone entonces abrir exploratoriamente las puertas a la identificación de factores de índole discursiva, económica, social y política que han posibilitado la transformación - por vía de la judicialización- de un problema público ambiental.

\section{De la conformación global de la cuestión ambiental a la proliferación local de conflictos socioambientales}

Toda comprensión sobre el estado de la naturaleza se basa en representaciones -afirma Hajer (1995) - y siempre supone un conjunto de prenociones y decisiones sociales que están mediadas por un conjunto determinado de prácticas discursivas. Esto no significa que la naturaleza allí afuera sea totalmente irrelevante, pero sí que la dinámica de la política y la conflictividad ambiental no pueden entenderse sin tomar en cuenta los discursos que guían nuestra percepción de la realidad.

Si los problemas ambientales desatados en distintas épocas y latitudes, como la deforestación en el siglo XIX, la erosión del suelo en la década de los treinta, la contaminación con pesticidas en los años sesenta y la energía nuclear en los ańos setenta eran concebidos como asuntos que requerían controles puntuales -es decir, que se abordaban a través de medidas paliativas ad hoc y ex post-, a partir de 1972 se comenzaron a generar nuevos discursos que transformaron el significado de la cuestión ambiental.

Según Hajer (1995), la publicación en ese año del informe Los límites del crecimiento -surgido de una conferencia de la ONU en la ciudad de Estocolmo- fue punta de lanza para la jerarquización institucional de las políticas ambientales y el inicio de una novedosa concepción, según la cual, la contaminación pasaría a ser vista como un problema estructural. Poco después, en 1980, se afianzaría un paradigma que se volvería hegemónico en la interpretación y acción sobre la cuestión ambiental, denominado modernización ecológica.

A la vez que reconoce el carácter sistémico de la problemática, este enfoque -que logró permear gran parte de las percepciones sociales sobre la relación sociedad-naturaleza- asumió que las instituciones políticas y económicas son capaces de internalizar el cuidado del ambiente. Así, la degradación ambiental se vuelve un asunto calculable y, por lo tanto, 
conciliable con el crecimiento económico; más aún, este discurso acaba siguiendo una lógica utilitaria según la cual, en el fondo, la prevención de la contaminación es redituable.

Debido a cuatro motivos -prosigue Hajer (1995)- esto se vuelve atractivo para los gobiernos: primero, porque se posiciona en contraposición a las estrategias de abordaje ex post que no daban resultados; segundo, porque usa el lenguaje de las empresas y conceptualiza la contaminación como una cuestión de ineficiencia, evitando la confrontación directa con las industrias; tercero, porque evita toda referencia explícita a las contradicciones sociales propias de otros discursos sobre el ambiente y, en lugar de llamar a cambios de fondo, es modernista y tecnocrático; y cuarto, porque tiene afinidad con las ideas neoliberales y a su vez permite esquivar las críticas estructurales de los ańos setenta: en el fondo, se basa en la creencia en el progreso, la técnica y la ciencia.

El discurso de la modernización ecológica se topó con una visión radicalmente distinta proveniente de los movimientos de justicia ambiental. Éstos pusieron en la cima de la agenda a las desigualdades que derivaban de la distribución asimétrica de los daños ecológicos y desafiaron con ello los discursos dominantes (Martínez, 2011).

$\mathrm{Al}$ juzgar los problemas ambientales en términos de absolutos morales y colocar los asuntos en clave de desafío a la Madre Tierra, estos movimientos adoptan una posición no negociable de rectitud moral, intocable por toda discursividad legal o científica. Así, la pregunta por lo pragmáticamente posible viraba hacia lo moralmente correcto (Harvey, 1996).

Cualquiera que sea el nivel de confrontación y preponderancia de estos discursos, lo cierto es que las últimas décadas han dado lugar a la conformación de un campo ambiental a nivel global que, como afirma Azuela (2006), no es otra cosa que un espacio social en el que entran en juego actores sociales con diferentes disposiciones frente a lo que todos reconocen, en principio, como problemas ambientales. En este proceso, los peligros presentados por los desarrollos tecnológicos y el cambio climático se volvieron el epicentro de una preocupación por la exposición social al riesgo (Beck, 1998).

Mientras tanto, la idea de desarrollo sustentable se convirtió, en contrapartida, en el foco de una coalición discursiva (Hajer, 1995) que engloba distintos enfoques y narrativas acerca de la cuestión ambiental, inclusive a actores económicos atraídos por las posibilidades que abre la internalización del conflicto para el capital (Merlinsky, 2013). Ya no se trata, por lo tanto, de la existencia o no de una crisis ambiental, sino de cómo se la interpreta (Hajer, 1995).

En este marco, la cuestión ambiental ha tendido a institucionalizarse a lo largo y ancho del globo: se sancionó nueva legislación nacional y 
supranacional, se crearon organismos gubernamentales con variables niveles de jerarquía abocados a la temática y se implementaron políticas diseñadas bajo argumentos de protección y cuidado del ambiente. Consistió, en otras palabras, en un proceso de globalización legal (Sieder et al., 2008) por el cual tratados y marcos legales ambientales se difundieron por el mundo hasta adquirir estatus jurídico en los niveles locales, a partir de la suscripción de acuerdos e incluso en sucesivas reformas constitucionales.

No obstante, la emergencia de esa institucionalidad no ha evolucionado en forma sincrónica en todas partes del mundo: en la Argentina, además de errática, la cuestión ambiental fue por muchos años un ámbito subsidiario en el conjunto de las políticas estatales. En los ańos ochenta se crearon organismos de segundo rango abocados a la formulación de iniciativas en torno a los recursos hídricos (sobre todo en las cuencas con usos productivos valiosos), y recién en la década de los noventa se alcanzó un grado subministerial por medio de la creación de la Secretaría de Recursos Naturales y Ambiente Humano (Merlinsky, 2013).

Asimismo, en 1994 una reforma constitucional reconoció el derecho al ambiente sano y, en 2002, el Congreso de la Nación sancionó la Ley General de Ambiente, que garantiza en su artículo 1 "presupuestos mínimos para el logro de una gestión sustentable y adecuada del ambiente, la preservación y protección de la diversidad biológica y la implementación del desarrollo sustentable" (Ley No 25.675, 2002).

La institucionalización de la problemática en torno al medio ambiente no se debió, por lo tanto, a un aumento de demandas sociales ni tuvo de por sí un paralelismo en términos de su instalación en la agenda pública. Sin embargo, la puesta en debate internacional de la cuestión ambiental -en un lugar crecientemente protagónico- y su posterior incorporación a los entramados del Estado nacional sí resultaron un factor ineludible para explicar el contexto en el cual, por primera vez, se suscitó en Argentina una inédita ola de conflictos ambientales a partir de 2003.

Fue desde entonces que estos nuevos derechos se tornaron exigibles y cobraron un amplio sentido social más allá de la letra de la ley, volviéndose fuente de argumentación en la arena pública y entrelazándose con los horizontes de inteligibilidad de los actores en conflicto.

Claro está, no puede desconocerse que mientras la cuestión ambiental penetraba la legislación y la institucionalidad estatal argentinas, las actividades basadas en la explotación de recursos naturales se extendían cada vez más hasta convertirse -producto de sus efectos sobre las poblaciones- en otro factor desencadenante del nuevo ciclo de conflictos. ${ }^{4}$

\footnotetext{
${ }^{4}$ El auge del extractivismo, así como el incremento en la cantidad e intensidad de los conflictos ambientales, no fue en aquellos años, ni lo es en la actualidad, una característica exclusiva de la Argentina. Más bien, proliferaron a lo largo y ancho de la región latinoamericana múltiples conflictos
} 
El caso del sector agropecuario es, a este respecto, uno de los más elocuentes: la expansión de la frontera agropecuaria derivaría en un aumento de la deforestación y las inundaciones (Arístide, 2014), así como en el desplazamiento de comunidades campesinas de sus unidades productivas (Barri y Wahren, 2010). En tanto, el cultivo de un nuevo tipo de soja transgénica conllevaría un creciente uso del glifosato como herbicida, cuestionado por sus implicancias sobre la salud (Avila-Vazquez et al., 2017).

La multiplicación de megaproyectos mineros, por su parte, daría lugar a un fenómeno análogo al de la agricultura: su instalación en zonas consideradas improductivas alteraría el equilibrio de los ecosistemas y presentaría amenazas a la salud y las economías de las poblaciones circundantes debido al vuelco de desechos tóxicos y la competencia por recursos como el agua y la energía eléctrica (Svampa et al., 2009).

En este contexto, la pequeña ciudad patagónica de Esquel -provincia de Chubut- se convirtió en 2003 en el epicentro del primer conflicto ambiental de resonancia nacional; cobró un simbolismo clave para la multiplicación de experiencias similares en diversas latitudes, así como una significativa reverberación mediática y política. En octubre de 2002, la empresa Meridian Gold presentó un informe de impacto ambiental para la explotación de oro que generaría alerta entre técnicos y ambientalistas de la región y conduciría a la primera asamblea de autoconvocados contra la megaminería.

Los altos niveles de movilización que sacudieron a Esquel desde entonces se enmarcaban en el clima de gran efervescencia social posterior a la crisis social, política y económica que había sacudido al país en 2001, pero fueron facilitados por una novedosa articulación entre un saber experto independiente -desarrollado y divulgado por grupos de profesionales que advertían sobre los riesgos de la puesta en marcha de una explotación minera de envergadura- y un lenguaje de valoración del territorio que se contraponía al de los promotores de esta actividad extractiva (Svampa et al., 2009).

Mientras que la empresa remarcaba la oportunidad que brindaban las minas en términos de empleo y "desarrollo", los vecinos movilizados destacaban que para ellos Esquel había sido una elección: de hecho, una buena parte de los habitantes provenían de grandes ciudades y su mudanza a la Patagonia se había debido a la búsqueda de un cambio en su estilo y calidad de vida.

vinculados con la actividad minera, la deforestación y la producción petrolera, entre otros. Numerosos autores han analizado este fenómeno, preguntándose conceptualmente por su naturaleza e implicancias sociales (Alfie, 2013; Folchi, 2001; Harvey, 1996; Napadensky y Azocar, 2017; Vallejos-Romero, 2008), así como también se han realizado estudios de casos, entre muchos otros, centrados en Chile (Bolados, 2014), Perú (Bebbington y Humphreys, 2009), Ecuador (Sánchez et al., 2016), Colombia (Güiza et al., 2015) y México (Brenner, 2010). 
El conflicto de Esquel se caracterizó por el desarrollo de una alta capacidad de presión por parte de la Asamblea de Vecinos Autoconvocados sobre el Concejo Deliberante y el gobierno provincial. Tras una marcha que logró la cancelación de una audiencia pública en la que se evaluaría el informe de impacto ambiental de Meridian Gold, el proceso de confrontación escaló hasta que los asambleístas finalmente lograron la convocatoria a un plebiscito. Éste se llevó adelante el 23 de marzo de 2003 y arrojó como resultado $81 \%$ de votantes en contra de la mina, sellándose así un rotundo rechazo al emprendimiento. Lejos de ser el último paso, la votación fue apenas el preámbulo para que poco después se votase una ley de prohibición de la minería a cielo abierto en todo el territorio de la provincia de Chubut.

El caso de Esquel se convirtió así en un momento fundacional para la conformación de una red nacional antiminera (Marín, 2009), que rápidamente comenzaría a tejerse en diversas localidades del conjunto del país. Como señalan Svampa et al. (2009), este conflicto tuvo un arrastre multiplicador que despertó a otras regiones donde ya se habían implantado -o estaban proyectándose- grandes yacimientos, y se volvió un caso testigo para las comunidades que se iban enterando de su destino minero. Así, tan temprano como en 2003 se conformaría una Red de Comunidades Afectadas por la Minería, integrada por miembros de numerosas provincias de la Argentina, sobre todo cordilleranas.

En la misma época en la que se llevaron a cabo las primeras asambleas contra la minería en Esquel, en la provincia de Córdoba inició una lucha cuyo ascenso -menos vertiginoso y más silencioso-ilustra la amplitud de las incipientes demandas ligadas al medio ambiente. En el barrio de Ituzaingó Anexo, situado a las afueras de la capital provincial -en los límites de la frontera agrícola-, un grupo de mujeres comenzaría a organizarse tras percibir un aumento dramático en la emergencia de enfermedades y dolencias como alergias y distintos tipos de cáncer. Por medio de protestas en la vía pública y la construcción de datos sobre los problemas de salud y sus patrones de aparición, lograron gradualmente instalar un debate acerca de los efectos de las fumigaciones y los agroquímicos.

Conocidas algunos años después como "Madres de Ituzaingó", este grupo se volvería insignia de un reclamo que de a poco se esparciría por diversas localidades de la pampa húmeda y pondría en cuestión el modelo de los agronegocios.

Mientras tanto, apenas a dos horas al norte de la ciudad de Buenos Aires, otro proceso comenzaba a desarrollarse cautelosamente para poco después convertirse en uno de los conflictos más importantes, complejos y prolongados de la década. El denominado "conflicto de las papeleras" comenzó en 2003 cuando habitantes de la localidad uruguaya de Fray Bentos 
advirtieron a un grupo de pares de la ciudad argentina de Gualeguaychú sobre la existencia de un proyecto para construir una fábrica de pasta de celulosa. Se trataba de un emprendimiento de la empresa española Ence, que se emplazaría sobre la orilla oriental del Río Uruguay, frontera natural entre ambos países.

En octubre, mientras el gobierno uruguayo le concedía a esta compañía los permisos ambientales y de construcción, los vecinos del lado argentino organizaron una primera marcha de protesta en el Puente Internacional General San Martín, la principal de las tres vías terrestres que conectan a las dos naciones. Por medio de la "Declaración del pueblo de Gualeguaychú" señalaron su oposición a la construcción de la planta de celulosa, rechazaron los estudios de impacto ambiental presentados por la empresa, convocaron a los municipios circundantes a movilizarse y se pronunciaron en contra del modelo de desarrollo presupuesto por ese tipo de emprendimientos.

Dos años más tarde, el otorgamiento por parte de Uruguay de un permiso a la empresa finlandesa Botnia para la instalación de otra fábrica de pasta de celulosa a pocos kilómetros de Ence -que por su magnitud se convertiría en una de las mayores del mundo en su tipo-operó como punto de quiebre para una radicalización del conflicto. El 30 de abril de 2005, más de 40,000 personas -casi la mitad de la población de la ciudad- se volcaron a las calles y se manifestaron en el puente internacional, incluyendo al intendente de Gualeguaychú y los de localidades circundantes.

La lucha contra las pasteras ya se volvía un asunto de público conocimiento a nivel nacional y comenzaba a ser objeto de preocupación gubernamental y roces diplomáticos. En los meses siguientes, el conflicto se robusteció y consolidó cuando los vecinos, constituidos formalmente como "Asamblea Ciudadana Ambiental de Gualeguaychú", apuntaron sus denuncias hacia el gobierno del país vecino por violación al tratado de uso compartido del Río Uruguay y comenzaron a realizar cortes (o piquetes) intermitentes en la ruta que conducía al puente.

El conflicto recrudeció aún más durante el 2006; la solidaridad de las asambleas ambientales de Concordia y Colón -ciudades donde se ubican los otros dos pasos internacionales- llevaría a bloqueos simultáneos de los tres puentes fronterizos y las movilizaciones contra las pasteras crecerían hasta convocar a más de 100,000 personas, captando primeras planas en la prensa argentina y de la región. Poco después, el gobierno presentó una demanda contra el país vecino ante la Corte Internacional de Justicia en la que denunció la falta de consulta previa a la instalación de las plantas, y el presidente Néstor Kirchner convocó a un acto en Gualeguaychú donde, ante decenas de miles de manifestantes, la totalidad de su gabinete y 19 gobernadores provinciales afirmaría que la cuestión ambiental era 
un asunto de "interés nacional". Para entonces, la escalada diplomática habría alcanzado su punto máximo y el medio ambiente se habría vuelto objeto privilegiado de discusión social.

Del conjunto de conflictos que se desarrollaban en diversas latitudes del país (mapa 1), el de las pasteras fue probablemente el que más logró

\section{Mapa 1 \\ Distribución geográfica de conflictos ambientales en Argentina ${ }^{5}$}

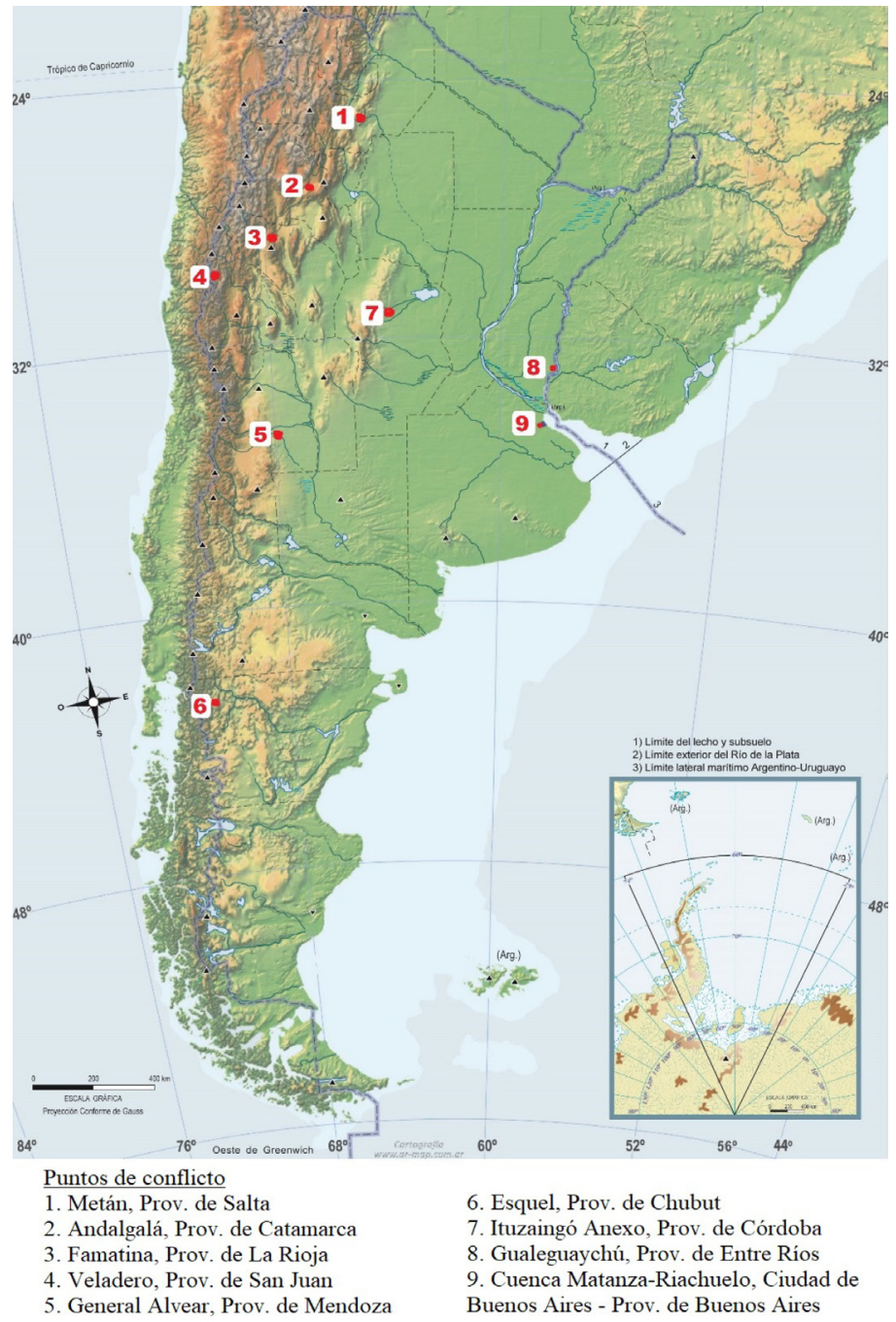

Fuente: elaboración propia.

${ }^{5}$ Distribución geográfica de algunos de los principales conflictos ambientales desarrollados en Argentina desde el inicio de la señalada ola de 2003. En el punto 9 se halla la cuenca MatanzaRiachuelo, que se encuentra bajo jurisdicción, tanto de la Provincia de Buenos Aires como de la Ciudad Autónoma de Buenos Aires. 
visibilizar las demandas ligadas a las consecuencias socioambientales de la explotación de recursos naturales; asimismo, resultó indispensable para la consolidación de una arena pública de deliberación sobre la cuestión ambiental (Merlinsky, 2013). Si los conflictos previos se habían ceñido a un nivel municipal o, cuanto mucho, habían logrado alcanzar una escala provincial, el de Gualeguaychú fue el primero en romper estos límites y convertirse en un asunto de discusión de primer orden en toda la Argentina. La visibilidad adquirida por este conflicto permitió que se volviese no sólo un asunto de debate por parte de múltiples actores sociales, sino un verdadero problema político-institucional para los gobiernos local, provincial y nacional.

La puesta en agenda de esta problemática, no obstante, no conllevó de por sí un cambio en la orientación de las políticas gubernamentales hacia la problemática ambiental ni tampoco una acumulación de fuerzas determinante para las asambleas ciudadanas. Los años subsiguientes darían cuentas de avances y retrocesos, así como diversos modos y grados de institucionalización de los conflictos.

En efecto, muchos hitos acontecieron desde que los sucesos en el Río Uruguay se volvieron el centro de atención nacional. En 2007, luego de la recolección de un millón y medio de firmas, el Congreso de la Nación sancionó una ley de protección de bosques nativos, cuyo cumplimiento, si bien ha sido escaso, contribuyó a poner en discusión los efectos de la deforestación en el noroeste del país.

En 2008 se sancionó una ley de protección de glaciares que fue inmediatamente vetada por la presidenta de la nación, Cristina Fernández de Kirchner, si bien dos años más tarde se aprobó una nueva versión de dicha ley, más permisiva y menos lesiva para los intereses de los emprendimientos mineros de alta montaña. En 2012, las luchas contra la minería alcanzaron su punto más alto cuando en Famatina, provincia de La Rioja, se desató una pueblada que nacionalizó la problemática como nunca antes (Svampa y Viale, 2014). Ese mismo ańo, se elevó por primera vez a juicio en la provincia de Córdoba la fumigación con agroquímicos, profundizándose los cuestionamientos al glifosato y sus efectos sobre la salud humana.

Estos son apenas algunos de los hitos que dan cuenta del crecimiento de la conflictividad ambiental y las formas en que éste se institucionalizó. En Buenos Aires, mientras tanto, el río más contaminado del país continuaba fuera del escrutinio público y permanecía ajeno a mayores controversias. Pero el ingreso de la cuestión ambiental a la agenda pública a nivel nacional hallaría un correlato local y la contaminación del Riachuelo adquiriría nuevos modos de tratamiento social. 


\section{Una nueva problematización social del estado de la cuenca}

El Riachuelo (mapa 2) -especialmente la zona de su desembocadura- fue históricamente intenso en materia de conflictividad social y organización popular. Las villas lindantes al río, caracterizadas por luchas reivindicativas de larga data en materia de acceso a la vivienda y servicios públicos -entre otras demandas- son uno de los ejemplos más acabados, pero sobresalen también formas asociativas más recientes como organizaciones vecinales y grupos de protesta conformados $a d$ hoc a raíz de la identificación de problemas comunes. Es el caso, por ejemplo, de las resistencias a la instalación de plantas de coque o las movilizaciones contra el tendido de cableados de alta tensión (Merlinsky, 2013).

\section{Mapa 2}

\section{Superficie de la cuenca Matanza-Riachuelo ${ }^{6}$}

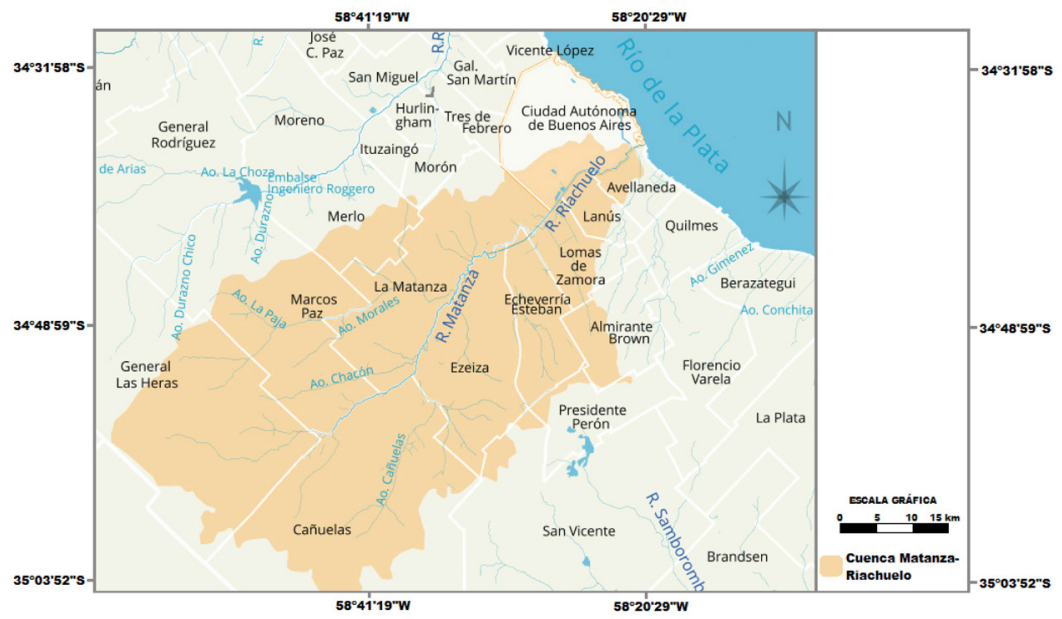

Fuente: elaboración propia a partir de mapa del Observatorio Metropolitano del Consejo Profesional de Arquitectura y Urbanismo (s/f).

Pero trátese de reclamos por la urbanización de barrios informales o del rechazo a industrias y obras eléctricas, las demandas sociales no se tramitaron de inicio en términos ambientales, pero sí estuvieron insertas en un campo de demandas y discursos orientados hacia una problematización de dicho tipo; del mismo modo, el hecho de que tuviesen un origen geográfico en la cuenca no conllevó automáticamente a que ésta se volviese un espacio de referencia como tal.

${ }^{6}$ Este territorio conforma junto con sus afluentes una cuenca hidrográfica de $2238 \mathrm{~km}^{2}$ que abarca 14 municipios y cuenta con más de ocho millones de habitantes. Este mapa grafica cómo el río -conocido comúnmente como Riachuelo- cuenta en efecto con dos tramos de nombres diferentes, que en su conjunto le dan su nombre a la cuenca: Matanza y Riachuelo. 
El activismo en La Boca es posiblemente un ilustrativo ejemplo del proceso de ambientalización de las demandas y marcos cognitivos de los actores de la cuenca. Este barrio lindante con el Riachuelo, que combina una población de clase media con zonas de clase trabajadora, se caracterizó desde la década de los noventa por la proliferación de agrupaciones abocadas a reclamar mejoramientos edilicios, el estado de las calles y las asiduas inundaciones.

A partir de la década siguiente, en el marco del auge de la conflictividad ambiental en el país, estas reivindicaciones comenzaron a articularse entre sí unificándose sus marcos de referencia en torno a la necesidad de alcanzar un saneamiento del río.

La Asociación de Vecinos La Boca, acaso la más importante de este tipo de organizaciones, surgió de la mano de reclamos por el mejoramiento de los efectores de salud, el espacio público y mayor seguridad ante los delitos, pero paulatinamente sus demandas comenzaron a reencuadrarse, desplazándose hacia el estado ambiental del Riachuelo: "por más espectaculares que sean los secuestros, robos y asesinatos de cada día, la inseguridad también es ambiental, y se cobra muchas más vidas que la violencia callejera” (Asociación de Vecinos La Boca, 2004). Así, se volvieron uno de los primeros (y pocos) actores territoriales en preguntar públicamente por el destino de los fondos del "plan de los mil días" y en interpelar a las autoridades en búsqueda de los responsables del saneamiento del río (Merlinsky, 2013).

Aunque la ambientalización de las demandas de grupos como éste era cada vez mayor -en sintonía con los procesos en desarrollo en el resto del país-, aún no existía entre ellos un punto de vista ecosistémico e integral de la cuenca Matanza-Riachuelo. Claro está, se trataba de actores con una inscripción territorial local, cuyas reivindicaciones se ceñían a los problemas que afectaban a sus vidas cotidianas en sus lugares de residencia.

Del mismo modo que el reclamo por el polo petroquímico ubicado en la cuenca baja se limitaba a ese establecimiento, o que una determinada protesta contra un basural a cielo abierto no se extendía hacia un cuestionamiento al sistema de gestión de residuos -si del punto de vista de los actores dependiera- la cuenca estaba atomizada. Más aún, si acompańamos el teorema de Thomas y Thomas (1928) de que si los individuos definen las situaciones como reales, éstas son reales en sus consecuencias, podría extenderse la afirmación anterior asegurando que la cuenca Matanza-Riachuelo, de hecho, no existía socialmente.

La construcción de una nueva perspectiva requeriría su articulación con saberes expertos y actores institucionales. Sólo de este modo la dispersión de reclamos y visiones confluirían para conformar un nuevo problema público. 


\subsection{Las organizaciones no gubernamentales (ONG)}

Las organizaciones no gubernamentales fundadas con el objetivo de proteger y defender el medio ambiente cumplieron un rol fundamental en la propulsión del Riachuelo a la agenda pública. Se trata de instituciones no estatales compuestas por profesionales que, si bien cuentan con diversas ideologías, formas de financiamiento y estrategias de acción, tienen en común el propósito central de influir sobre las políticas medioambientales (Bryant y Bailey, 1997; Mermet et al., 2001). Resaltan entre ellas Greenpeace, que se sustenta con aportes particulares y se especializa en el despliegue de campañas de comunicación masiva mediante acciones de alto impacto mediático y visibilidad pública, así como la Fundación Ambiente y Recursos Naturales (FARN), que se financia con contribuciones de empresas y organismos internacionales y sobresale por abocase a influir en tomadores de decisiones mediante el lobby y la formación de opinión. Organizaciones como éstas fueron pioneras en la realización de actividades públicas -tales como talleres, foros o seminarios- por medio de las cuales se presentó públicamente el problema de la degradación ambiental de la cuenca Matanza-Riachuelo (Merlinsky, 2013: 84).

Estas ONG, en su mayoría consolidadas durante los años noventa, han centrado su accionar en las herramientas y los canales brindados por la reforma de la Constitución Nacional de 1994. Además de otorgar estatus constitucional al derecho al ambiente sano, la nueva Carta Magna institucionalizó mecanismos participativos como la iniciativa popular, la consulta popular y las audiencias públicas, además de consagrar los derechos de incidencia colectiva. Se trata de derechos transindividuales que pertenecen a un grupo indeterminado de personas y permiten que cualquier ciudadano, directa o indirectamente afectado por la violación de tal o cual derecho, pueda recurrir a la justicia (Merlinsky, 2013).

Las implicancias de estas modificaciones constitucionales fueron sustanciales para las organizaciones ambientalistas. Al contar con aptitud legal para accionar judicialmente se volvieron capaces de interponer acciones de amparo en defensa de los derechos de incidencia colectiva, tales como el derecho al ambiente sano resguardado por el artículo 41 de la Constitución. De este modo, adquirieron la legitimidad jurídica de representar el interés general de la población, mientras que el litigio se convirtió en una vía que adquiriría cada vez mayor centralidad en sus repertorios de acción política. 


\subsection{Los informes JICA}

A raíz de un convenio de monitoreo ambiental del Polo Petroquímico Dock Sud -situado cerca de la desembocadura del río-, en 2002 se dieron a conocer los resultados de un estudio financiado por la Agencia Japonesa de Cooperación Ambiental (JICA, por sus siglas en inglés) que arrojó una alarmante concentración de contaminantes como benceno, tolueno y xileno (BTX) en el aire de la zona. El año siguiente, como parte del mismo programa, otra etapa de la investigación -en este caso epidemiológica- indicaría que $50 \%$ de la población infantil del barrio aledaño contaba con altos niveles de plomo en sangre.

Los informes científicos de JICA cobraron repercusión social tan pronto como fueron difundidos. Por un lado, al brindar pruebas sólidas sobre la contaminación de los cuerpos se convirtieron en el punto de partida para la puesta en debate de las condiciones de vida de la población de Villa Inflamable (barrio popular situado en las proximidades del predio). Sin embargo, como se advirtió, estos datos fueron más apropiados por actores ajenos al barrio como organizaciones ambientalistas o medios de comunicación que por sus propios habitantes, para quienes la nueva información alimentó temores antes que contribuir a la construcción de una orientación política colectiva.

Los estudios ambientales se volvieron un insumo científico indispensable para los actores que buscaban poner en cuestión la situación ambiental de Dock Sud o de otras zonas bañadas por el Riachuelo. Sólo faltaba que éstos se articulasen, confluyendo en una mirada común sobre lo que estaba en juego allí a lo largo del río.

\subsection{El Defensor del Pueblo}

El Defensor del Pueblo es un órgano independiente creado a partir de la reforma constitucional de 1994 que "[actúa] con plena autonomía funcional, sin recibir instrucciones de ninguna autoridad" y tiene como misión "la defensa y protección de los derechos humanos y demás derechos, garantías e intereses tutelados en esta Constitución y las leyes, ante hechos, actos u omisiones de la Administración; y el control del ejercicio de las funciones administrativas públicas" (Constitución de la Nación Argentina, 1994). Desde su creación, el organismo había recibido cuantiosas denuncias de uno u otro modo ligadas a la situación ambiental de la cuenca, sea por afecciones en la salud, la suciedad del río o la contaminación generada por el Polo Petroquímico.

Dicha suma de reclamos individuales cobraron otro cariz cuando en 2002, a raíz de un reclamo puntual presentado por la Asociación de 
Vecinos La Boca (2004), el Defensor del Pueblo creó una Unidad de Investigaciones Especiales destinada a controlar y sistematizar la totalidad de las denuncias presentadas. Ésta se planteó como objetivos: a) "diagnosticar el estado de situación de la cuenca Matanza-Riachuelo en sus distintos aspectos"; $b$ ) "elaborar un informe especial tendente a reafirmar la gravedad de esta problemática y, por lo mismo, a reiterar la necesidad de medidas concretas por parte de las autoridades responsables", y c) "sugerir líneas de acción relativas a esas medidas necesarias y urgentes que permitan recomponer el ambiente de la cuenca y así preservar la salud de la población mediante un adecuado manejo del recurso natural" (Defensor del Pueblo de la Nación et al., 2003: 9).

Con el fin de dar respuesta a dichos objetivos, el Defensor del Pueblo convocó a organizaciones no gubernamentales, universidades y grupos vecinales, con los cuales en 2003 presentaron un primer documento. Titulado "Informe especial sobre la cuenca Matanza-Riachuelo", este trabajo analizaba en clave histórica, ambiental e institucional el estado de situación del territorio, colocando el foco en las condiciones de salubridad e infraestructura y proponiendo diagnósticos y medidas para su saneamiento.

A su vez, el estudio ofreció un enfoque original al hacer énfasis en la cuestión sociosanitaria, enumerando las principales enfermedades provocadas por la degradación del ambiente y estableciendo vinculaciones con las diferentes fuentes de contaminación. En tanto realizaba un seguimiento de la ejecución de los presupuestos de las políticas previamente implementadas, brindó asimismo un punto de partida para supervisar y realizar pedidos de informes a las agencias responsables, sobre todo el "Comité Ejecutor Matanza Riachuelo", que se había creado en la década anterior con motivo del fallido plan de los mil días.

Frente a la dispersión de enfoques y falta de conocimientos objetivados, el documento permitió encolumnar tras un mismo ariete a actores con diversas necesidades, intereses y visiones, reorientando el sentido de sus demandas y consolidando a la cuenca como territorio de referencia y problematización. Más aún, el informe se transformó en una exitosa palabra autorizada para la presentación de la degradación ambiental como asunto público: cuando en mayo de 2006 -en pleno auge del conflicto por las plantas de pasta de celulosa- sus autores presentaron un nuevo estudio, las repercusiones sociales, políticas y mediáticas fueron ampliamente mayores. Apenas un mes más tarde, la Corte Suprema recogería el guante generando un cambio sin precedentes en la historia de la cuenca Matanza-Riachuelo. 


\section{Crisis política y deslegitimación de la Corte Suprema. Hacia un relanzamiento en clave ambiental}

En el primer apartado se analizó el surgimiento de la cuestión ambiental a nivel internacional y cómo cobró entidad en el plano nacional, en primer lugar mediante su incorporación a los entramados jurídicos y, en segundo término, a partir de una ola de conflictos a lo largo y ancho del país. En el segundo apartado se planteó el proceso de ambientalización de las demandas y discursos, deteniéndonos a su vez en el papel que cumplieron una serie de eventos e instituciones en la conformación de una perspectiva integral sobre la zona del Riachuelo. Con base en este recorrido, la sección actual recuperará los sucesos de la introducción -que relatan la judicialización del conflicto del Riachuelo- para agregar una nueva dimensión que da cuenta del contexto social y político que condujo a la Corte Suprema a declarar su competencia sobre la cuestión y con ello impulsar el inicio de una nueva etapa.

En el 2006, el máximo tribunal colocó bajo su órbita la denuncia realizada por los vecinos de la cuenca; no obstante, estaba todavía muy cercana la crisis nacional que había eclosionado en 2001, la cual, además de dar en tierra con el modelo de la convertibilidad monetaria que regía desde 1991, había expuesto las profundas desconfianzas en el sistema de partidos y el régimen político en general. Si bien Néstor Kirchner, quien asumió en 2003 la presidencia, había logrado restaurar la autoridad presidencial, gozaba de alta popularidad y estaba comandando un nuevo ciclo de crecimiento económico, la confianza popular en las instituciones del Estado no lograba recomponerse.

En 2001, las plazas del país se desbordaban al clamor de "que se vayan todos", un cántico que expresaba el hartazgo social con las condiciones de vida y especialmente con los partidos políticos. El nuevo bloque al mando del Poder Ejecutivo había reconocido este agotamiento: durante sus primeros años, el kirchnerismo desistió de reposar sobre la estructura partidaria que formalmente lo había llevado al poder -el Partido Justicialista- para construirse más bien sobre un proyecto de transversalidad que buscaba incorporar tanto a sectores de un partido históricamente opuesto -la Unión Cívica Radical- como a grupos piqueteros y movimientos sociales que habían marcado el ritmo de la conflictividad en la etapa previa y aún guardaban un significativo poder de movilización.

La Corte Suprema no había quedado exenta del descreimiento y el rencor populares. Durante la década de los noventa, sus fallos invariablemente favorables al gobierno -en especial mediante los votos de cinco jueces designados por el presidente Carlos Menem, conocidos como la "mayoría automática"- expresaban una sumisión a los designios del poder 
político. Encubridora de hechos de corrupción ligados a funcionarios, apañadora de actos ilícitos en el marco del programa de privatización de empresas públicas y sostén jurídico de las reformas políticas y económicas llevadas a cabo por el gobierno, la Corte Suprema se había vuelto el foco de escándalos de todo tipo.

Los meses más álgidos de la crisis de 2001 también la habían colocado en el ojo de la tormenta, cuando apañó la controversial medida del presidente Fernando de la Rúa conocida como corralito. Decretada el 3 de diciembre de 2001, esta decisión restringía la libre disposición del dinero depositado en cuentas corrientes, cajas de ahorro y plazos fijos, limitando las extracciones a un monto máximo semanal. Como consecuencia, los denominados ahorristas se volcaron a las calles, protestando con cacerolas en las puertas de los bancos por la retención de sus depósitos.

Cuando la crisis llegó a su punto cúlmine con un estallido social el 19 y 20 de diciembre, las movilizaciones se dirigirían no solamente al Congreso de la Nación y a la Casa Rosada -sedes del Poder Legislativo y Ejecutivo, respectivamente-, sino también al Palacio de Justicia. Denunciada como cómplice del proceso que había desencadenado semejantes penurias económicas, la Corte Suprema veía cómo el grito de "que se vayan todos" arribaba a sus mismísimas puertas.

Nuevamente, el gobierno de Néstor Kirchner tomó nota de la posición crítica en la que se hallaba la máxima autoridad judicial. Interpretando las protestas que todavía clamaban por la renuncia de sus integrantes y asumiendo la necesidad de una renovación institucional, en 2003 el presidente exigió por cadena nacional de radio y televisión que el Congreso pusiera en marcha un juicio político contra los miembros de la "mayoría automática", acusándola de actuar "a espaldas de la sociedad" y de no estar "a la altura de las circunstancias".

Poco después, tres de esos jueces renunciarían y otros dos que optaron por resistir en sus cargos serían depuestos, tras lo cual se firmó un decreto presidencial que limitaba las capacidades del Poder Ejecutivo para nombrar magistrados y transparentaba los mecanismos de designación. Así, tras la asunción de nuevos jueces, culminaba un proceso de depuración de la Corte Suprema y se abría otra etapa, también, en la cúspide del Poder Judicial.

Pero las impugnaciones sociales contra el sistema judicial estaban lejos de haber culminado. El 17 de marzo de 2004 el secuestro extorsivo y posterior asesinato de un joven de 23 años, Axel Blumberg, conmovió al país. Su padre, Juan Carlos Blumberg, corporizó la puesta en agenda de la inseguridad como asunto de preocupación social de primer orden y encabezó movilizaciones multitudinarias que, a la vez que le reclamaban al Congreso el endurecimiento de las penas y le exigían al gobierno un cambio en las políticas de seguridad, expresaban un potente malestar con el 
Poder Judicial, acusado de incapaz de hacer justicia, cuando no cómplice de los crímenes y delitos.

La nueva Corte Suprema precisaba recomponer su legitimidad; la denuncia por daños y perjuicios provocados por el Riachuelo brindaba una oportunidad; por un lado, uno de sus integrantes, Ricardo Lorenzetti - pocos meses después del fallo nombrado presidente del tribunal- era uno de los principales especialistas en el país en derecho ambiental, lo que le otorgaba al cuerpo de jueces un determinado savoir faire para la conducción de una causa vinculada a la restauración de un daño colectivo y la protección del derecho al ambiente sano. Hacia 2006, por otro lado, los conflictos ambientales estaban generando una presión cada vez grande para insertarse en la agenda estatal. Mientras tanto, la sensibilidad política y social en torno a la cuestión ambiental -es decir, su peso relativo en las percepciones y preocupaciones de los actores- se había incrementado y, fundamentalmente, se hallaba en plena ebullición el conflicto por las pasteras del Río Uruguay. Según Merlinsky:

es importante prestar atención a la sincronía de los acontecimientos [...] pues entre 2005 y 2006, mientras el [conflicto de Gualeguaychú] ganaba espacio en los medios de comunicación y el propio presidente Kirchner mencionaba que el tema ambiental era parte de la agenda del Estado, la Defensoría del Pueblo de la Nación presentó los informes [...] que denunciaban el grave estado de situación de Riachuelo [...] De modo tal que el "caso Riachuelo" fue ganando visibilidad pública a la luz de esa progresiva politización del conflicto del Río Uruguay (2013: 117).

El estado de movilización en Gualeguaychú contra las fábricas de pasta de celulosa daba cuenta ejemplar de una generación de demandas sociales que pujaban por ser oídas, mientras que la situación del Riachuelo retrataba los fracasos del Estado argentino en la construcción de una gobernabilidad ambiental, así como el relegamiento de un problema que afectaba a millones de habitantes. Al dictar una sentencia que apuntaba a generar soluciones duraderas para un problema histórico, organizando a distintos niveles de gobierno alrededor de sus mandatos, la Corte Suprema se relanzaba socialmente y construía un punto de inflexión en la política ambiental.

\section{Conclusiones}

A lo largo de este artículo hemos examinado el proceso de emergencia de la causa Mendoza, que apuntó a construir una reparación sin precedentes sobre un territorio históricamente olvidado, objeto de desaprensión y negligencias. En un sentido inmediato, vimos que la impronta y jerarquía de esta etapa fue producto de la generación, por parte de la Corte 
Suprema, de un "caso estructural" (Puga, 2014), por el cual se conminaba a múltiples agencias estatales a buscar soluciones duraderas a la vulneración masiva de derechos, incluso más allá de las pretensiones e intereses de los denunciantes originales. Pero la propuesta de estas páginas fue asumir que la declaración de competencia originaria, con base en la cual tuvo inicio la causa, en sí misma no puede ser entendida sino como contingente.

La preocupación aquí ha reposado sobre las condiciones de posibilidad del inicio, dentro del largo derrotero del Riachuelo, del capítulo actual de judicialización. Para ello, seguimos un camino -acaso weberiano- de imputación causal, indagando en distintas dimensiones (políticas, sociales), escalas (local, global) y temporalidades (corta, larga) que expliquen el porqué del inicio de un proceso que volvió la degradación ambiental de la cuenca un asunto de preocupación social y atención institucional como nunca antes.

En primer lugar, se hizo hincapié en la conformación mundial de un campo de deliberación e institucionalización política de la cuestión ambiental. El reconocimiento generalizado de problemas globales como el cambio climático coaligó a diversos actores en torno al discurso del desarrollo sustentable y, asimismo, llevó al diseño de políticas estatales y marcos legales que se abocarían a combatir el riesgo presentado por el deterioro del ambiente.

Por medio de un proceso de "globalización legal" (Sieder et al., 2008), estos entramados legislativos y discursivos penetraron la institucionalidad jurídica del Estado argentino y, a partir del desarrollo de una ola de conflictos catalizados por la proliferación de actividades extractivas y de alto impacto territorial, se localizaron en términos sociales, construyéndose la problemática ambiental como un asunto de alta visibilidad en la agenda pública. En otras palabras, lo discursivo, lo institucional, lo económico y lo social confluyeron para catapultar a la cuestión ambiental en tanto marco de tratamiento del problema del Riachuelo.

En segundo lugar, colocamos la lupa en el Riachuelo para dar cuenta de las repercusiones que allí comenzó a tener la construcción de un campo de demandas ambientales a nivel nacional. A partir del caso de la Asociación de Vecinos La Boca (2004), examinamos cómo se ambientalizaron los grupos y reclamos, y nos detuvimos en el papel que tuvieron un conjunto de eventos (los informes JICA), organizaciones (las ONG ambientalistas) y organismos (el Defensor del Pueblo) en la articulación de demandas y puntos de vista, encuadrando la problemática en clave de cuenca. Observamos cómo, de esta manera, el problema de la contaminación adquirió un renovado estatus en la agenda pública.

Por último, el foco estuvo puesto en las circunstancias de orden más inmediato que derivaron en el relanzamiento de la Corte Suprema en 
clave ambiental. Sostuvimos que la crisis política, económica y social que tuvo su epicentro en los acontecimientos de 2001 generó asimismo una crisis de legitimidad que se volcó sobre el propio Poder Judicial.

El juicio político a los miembros de la mayoría automática del periodo menemista, los cuestionamientos a la justicia en el marco de los crecientes reclamos de seguridad y la experticia de uno de sus nuevos integrantes en derecho ambiental confluyeron para la toma de decisión por parte del tribunal de declarar su competencia originaria ante la denuncia de los vecinos de Avellaneda, y transformar con ello el posicionamiento social e institucional de la problemática del Riachuelo.

Claro está, la transformación del conflicto del Riachuelo a partir de su ingreso en la justicia debe entenderse en el marco de la gradual expansión de la esfera jurídica acontecida en Argentina tras la recuperación democrática. Desde entonces, el fortalecimiento del sujeto y el Estado de derecho como ordenadores sociales y culturales -en contraposición a épocas donde la interrupción constitucional, la proscripción y la violencia política eran moneda corriente- han abonado a una creciente tramitación de la conflictividad por vía judicial, y con ello también a una mayor presencia del derecho en los horizontes de expectativas de los actores sociales.

La judicialización en la cuenca debe por ende analizarse como parte de cambios de largo alcance en la relación entre la sociedad y el propio derecho, entendido como puerta de acceso a la problematización de la realidad ambiental.

\section{Fuentes consultadas}

Alfie, Miriam (2013), "Democracia deliberativa y gobernanza ambiental: ¿conceptos transversales de una nueva democracia ecológica?", Sociológica, 29 (80), Ciudad de México, Universidad Autónoma Metropolitana unidad Azcapotzalco, pp. 73-122.

Aliste, Enrique y Stamm, Caroline (2016), "Hacia una geografía de los conflictos socioambientales en Santiago de Chile: lecturas para una ecología política del territorio", Revista de Estudios Sociales, núm. 55, Bogotá, Universidad de los Andes, pp. 45-62.

Andreu Abela, Jaime Jose (2002), Técnicas de análisis de contenido: una revisión actualizada, Barcelona, Fundación Centro de Estudios Andaluces. 
Arístide, Pablo (2014), "Apropiación de la naturaleza en agroecosistemas y bosques del Chaco semiárido (Santiago del Estero, Argentina)", tesis de doctorado, Universidad de Buenos Aires, Facultad de Ciencias Exactas y Naturales, Buenos Aires, <https://bibliotecadigital.exactas.uba.ar/collection/tesis/document/tesis_n5619_ Aristide>, 9 de marzo de 2020.

Avila-Vazquez, Medardo; Maturano, Eduardo; Etchegoyen, Agustina; Difilippo, Silvina y Maclean, Bryan (2017), "Asociación entre cáncer y exposición ambiental a glifosato”, International journal of clinical medicine, 8 (2), Irvine, Scientific Research Publishing, pp. 73-85, <http://reduas.com.ar/wp-content/uploads/downloads/2017/02/txt-ca-y-glifo-espa\%C3\%B1ol.pdf>, 12 de septiembre de 2019.

Asociación de Vecinos La Boca (2004), "S.O.S. Riachuelo", EcoPortal. net, <https:/www.ecoportal.net/temas-especiales/agua/seguridad_ambiental__s-_o-_s-_riachuelo_-_2004/?cn-reloaded =1>, 12 de marzo de 2020.

Azuela, Antonio (2006), Visionarios y pragmáticos. Una aproximación sociológica al derecho ambiental, Ciudad de México, Universidad Nacional Autónoma de México-Instituto de Investigaciones Sociales/Editorial Fontamara.

Azuela, Antonio y Cosacov, Natalia (2013), “Transformaciones urbanas y reivindicaciones ambientales. En torno a la productividad social del conflicto por la construcción de edificios en la Ciudad de Buenos Aires", Eure, 39 (118), Santiago de Chile, Pontificia Universidad Católica de Chile, pp. 149-172.

Barri, Fernando y Wahren, Juan (2010), "El modelo sojero de desarrollo en la Argentina: tensiones y conflictos en la era del neocolonialismo de los agronegocios y el cientificismo-tecnológico", Realidad Económica, núm. 255, Buenos Aires, Instituto Argentino para el Desarrollo Económico, pp. 43-65.

Bebbington, Anthony y Humphreys Bebbington, Denise (2009), "Actores y ambientalismos: conflictos socio-ambientales en Perú", Íconos. Revista de Ciencias Sociales, núm. 35, Quito, Flacso Andes, pp. 117-128. 
Beck, Ulrich (1998), La sociedad del riesgo. Hacia una nueva modernidad, Barcelona, Paidós Ibérica.

Bolados, Paola Alejandra (2014), "Los conflictos etnoambientales de 'Pampa Colorada' y 'El Tatio' en el salar de Atacama, norte de Chile. Procesos étnicos en un contexto minero y turístico transnacional", Estudios Atacameños, núm. 48, San Pedro de Atacama, Universidad Católica del Norte, pp. 229-248.

Bourdieu, Pierre (1987), "The force of law: toward a sociology of the juridical field", Hastings Law Journal, 38 (814), San Francisco, University of California, pp. 814-853.

Brenner, Ludger (2010), "Gobernanza ambiental, actores sociales y conflictos en las áreas naturales protegidas mexicanas", Revista Mexicana de Sociología, 72 (2), Ciudad de México, Universidad Nacional Autónoma de México, pp. 283-310.

Bryant, Raymond y Bailey, Sinéad (1997), Third world political ecology, Londres, Routledge.

Clarín (2006), "Los mil días de María Julia”, Diario Clarín, 25 de agosto, Buenos Aires, <https://www.clarin.com/ediciones-anteriores/ mil-dias-maria-julia_0_Hyfq6mJRFe.html>, 12 de septiembre de 2019.

Clichevsky, Nora (2002), "Pobreza y políticas urbano-ambientales en Argentina”, documento de trabajo núm. 49, serie Medio Ambiente y Desarrollo, Santiago de Chile, United Nations Publications.

Cobb, Roger; Ross, Jennie-Keith y Ross, Marc Howard (1976), "Agenda building as a comparative political process", The American political science review, 70 (1), Washington, American Political Science Association, pp. 126-138.

Constitución de la Nación Argentina (1994), “Artículo 86", 15 de diciembre, Buenos Aires, República Argentina, <http://servicios.infoleg. gob.ar/infolegInternet/anexos/0-4999/804/norma.htm>, 24 de agosto de 2020.

Corte Suprema de Justicia de la Nación (2008), "Mendoza, Beatriz Silvia y otros c/ Estado Nacional y otros s/ daños y perjuicios (daños derivados de la contaminación ambiental del Río 
Matanza-Riachuelo)", 8 de julio, Buenos Aires, Corte Suprema de Justicia de la Nación, <http://www.saij.gob.ar/corte-supremajusticia-nacion-federal-ciudad-autonoma-buenos-aires-mendozabeatriz-silvia-otros-estado-nacional-otros-danos-perjuicios-danosderivados-contaminacion-ambiental-rio-matanza-riachuelofa08000047-2008-07-08/123456789-740-0008-0ots-eupmocsollaf>, 9 de marzo de 2020 .

Defensor del Pueblo de la Nación, Asociación Vecinos La Boca, Centro de Estudios Legales y Sociales, Defensoría Adjunta de la Ciudad de Buenos Aires, Fundación Ambiente y Recursos Naturales, Fundación Ciudad; Poder Ciudadano y Universidad Tecnológica Nacional (2003), "Informe especial sobre la cuenca MatanzaRiachuelo", Buenos Aires, Defensor del Pueblo de la Nación, $<$ http://bam21.org.ar/comunidad/pluginfile.php/1509/mod_ data/content/4618/Informe\%20especial\%20sobre\%20la $\% 20$ cuenca\%20Matanza\%20Riachuelo.\%202003.pdf>, 9 de marzo de 2020 .

Di Paola, María Eugenia; Sangalli, Federico y Caorsi, Silvina (2009), Informe Ambiental Anual 2009, Buenos Aires, Fundación Ambiente y Recursos Naturales.

Espinosa Hernández, Rolando (2015), "Conflictos socioambientales y pobreza: el caso de la zona metropolitana de la Ciudad de México", Cuadernos de Geografia: Revista Colombiana de Geografía, 24 (1), Bogotá, Universidad Nacional de Colombia, pp. 193-201.

Folchi, Mauricio (2001), "Conflictos de contenido ambiental y ecologismo de los pobres: no siempre pobres, ni siempre ecologistas”, Ecología política, núm. 22, Barcelona, Fundación ENT/Icaria Editorial, pp. 79-100.

Fuks, Mario (1998), "Arenas de ação e debate públicos: conflitos ambientais e a emergência do meio ambiente enquanto problema social no Rio de Janeiro", Dados, 41 (1), Río de Janeiro, Universidade do Estado do Rio de Janeiro.

Fundación Ambiente y Recursos Naturales, Centro de Estudios Legales y Sociales, Greenpeace Argentina, Asociación Ciudadana por los Derechos Humanos y Vecinos de La Boca (2017), "9 años del fallo de la Corte. Una política de Estado todavía ausente”, Buenos Aires, Fundación Ambiente y Recursos Naturales/Centro de 
Estudios Legales y Sociales/Greenpeace Argentina/Asociación Ciudadana por los Derechos Humanos/Vecinos de La Boca, <https:/www.cels.org.ar/web/wp-content/uploads/2017/07/ Riachuelo-informe-a-9-a\%C3\%B1os-del-fallo-de-la-CSJN.pdf>, 12 de septiembre de 2019.

Guerrero-Bernal, Juan-Carlos; Márquez Murrieta, Alicia; Nardacchione, Gabriel Andrés y Pereyra, Sebastian (2018), "Estudio introductorio", en Juan Carlos Guerrero Bernal, Alicia Márquez Murrieta, Gabriel Nardacchione y Sebastian Pereyra (coords.), Problemas públicos. Controversias y aportes contemporáneos, Ciudad de México, Contemporánea, pp. 9-54.

Güiza, Leonardo; Londoño-Toro, Beatriz y Rodríguez Barajas, Cristhian David (2015), "La judicialización de los conflictos ambientales: un estudio del caso de la cuenca hidrográfica del río Bogotá (CHRB), Colombia", Revista internacional de contaminación ambiental, 31 (2), Ciudad de México, Universidad Nacional Autónoma de México, pp. 195-209.

Hajer, Maarten (1995), The politics of environmental discourse: ecological modernization and the policy process, New York, Oxford University Press.

Harvey, David (1996), "The environment of justice”, en David Harvey, Justice, nature \& the geography of difference, New Jersey, Blackwell Publishing, pp. 366-402.

Hilgartner, Stephen y Bosk, Charles (1988), “The rise and fall of social problems: a public arenas model”, American Journal of Sociology, 94 (1), Chicago, Universidad de Chicago, pp. 53-78.

Jordán Fuchs, Ricardo; Riffo Pérez, Luis y Prado, Antonio (2017), Desarrollo sostenible, urbanización y desigualdad en América Latina y el Caribe: dinámicas y desafios para el cambio estructural, Santiago de Chile, CEPAL/Cooperación Alemana.

Ley No 25.675 (2002), "Ley General del Ambiente", 6 de noviembre, Buenos Ares, República Argentina, <http://servicios.infoleg.gob. ar/infolegInternet/anexos/75000-79999/79980/norma.htm> 24 de agosto de 2020. 
Maciel, Matías y Groisman, Valeria (2003), "Cuenca hídrica Matanza-Riachuelo”, La gran ciudad, núm. 1, Buenos Aires, Fundación Metropolitana, pp. 4-15.

Mançano Fernandes, Bernardo (2012), "Movimentos socioterritoriais e movimentos socioespaciais: contribuição teórica para uma leitura geográfica dos movimentos sociais”, Revista Nera, 6 (8), São Paulo, Universidade Estadual Paulista, pp. 24-34.

Marín, Marcela Cecilia (2009), "El 'no a la mina' de Esquel como acontecimiento: otro mundo posible", en Maristella Svampa y Mirta Antonelli (eds.), Minería transnacional, narrativas del desarrollo y resistencias sociales, Buenos Aires, Biblos, pp. 181-204.

Martínez Allier, Joan (2011), El ecologismo de los pobres. Conflictos ambientales y lenguajes de valoración, Madrid, Icaria.

Melé, Patrice (2006), Pour une géographie de l'action publique: patrimoine, environnement et processus de territorialisation, Tours, Université de Tours-Habilitation à Diriger des Recherches.

Merlinsky, María Gabriela (2013), Política y justicia ambiental en la metrópolis de Buenos Aires. El conflicto del Riachuelo, Buenos Aires, Fondo de Cultura Económica.

Mermet, Lauren; Dziedziki, Jean y Laurans, Yann (2001), "ONG internationales et associations françaises”, en Michel Boyer, Guy Herzlich y Bruno Maresca (coords.), L'environnement, question sociale. Dix ans de recherches pour le ministère de l'environnement, París, Odile Jacob.

Napadensky, Aaron y Azocar, Ricardo (2017), “Espacios globales y espacios locales: en busca de nuevos enfoques a los conflictos ambientales. Panorámica sobre Sudamérica y Chile, 2010-2015”, Revista de Estudios Sociales, núm. 61, Bogotá, Universidad de los Andes, pp. 28-42.

Nápoli, Andrés y García Espil, José (2011), "Riachuelo: hacer hoy pensando en la cuenca del mañana”, en María Eugenia Di Paola, Federico Sangalli y Silvina Caorsi (eds.), Informe Ambiental Anual 2011, Buenos Aires, Fundación Ambiente y Recursos Naturales, pp. 177-208. 
Observatorio Metropolitano del Consejo Profesional de Arquitectura y Urbanismo (s/f), "Cuenca Matanza Riachuelo", Ciudad Autónoma de Buenos Aires, Consejo Profesional de Arquitectura y Urbanismo, <http://www.observatorioamba.org/planes-y-proyectos/cuencas/cuenca-matanza-riachuelo\#>, $18 \mathrm{de}$ agosto de 2020.

Palmett Plata, Olgalicia del Pilar (2016), "Externalidades ambientales ocasionadas por la urbanización en la ciudad de Medellín”, Procesos Urbanos, núm. 3, Sincelejo, Corporación Universitaria del Caribe/CECAR, pp. 38-54.

Puga, Mariela (2014), "El litigio estructural”, Revista de Teoría del Derecho de la Universidad de Palermo, núm 2, Buenos Aires, Universidad de Palermo, pp. 41-82.

QDA (Qualitative Data Analysis) (2017), ATLAS.ti Scientific Software Development GmbH, Versión 8.1, Berlin, Scientific Software Development GmbH.

Quimbayo Ruiz, Germán A. (2014), "Movimientos sociales, políticas y conflictos ambientales en la construcción de ciudad: El caso de Bogotá", Ecología Política, núm. 47, Barcelona, Fundación ENT, pp. 104-107.

Rocha, Laura (2005), "El Riachuelo, sucio desde 1811”, La Nación, 21 de junio, Buenos Aires, sección Sociedad, <https://www.lanacion. com.ar/sociedad/el-riachuelo-sucio-desde-1811-nid714665>, 12 de septiembre de 2019.

Rossi, Pietro (2012), “Introducción”, en Max Weber, Ensayos sobre metodología sociológica, Buenos Aires, Amorrortu, pp. 9-37.

Sánchez Vázquez, Luis; Espinosa, María Gabriela y Eguiguren, María Beatriz (2016), "Percepción de conflictos socio-ambientales en zonas mineras: El caso del Proyecto Mirador en Ecuador", Ambiente \& Sociedade, 19 (2), São Paulo, Associação Nacional de Pós-Graduação e Pesquisa em Ambiente e Sociedade, pp. 23-44.

Scharager, Andrés (2019), "Judicialización, política y conflicto social. Resistencias y controversias en un proceso de relocalización de villas en Buenos Aires (2008-2018)", tesis de doctorado, Univer- 
sidad de Buenos Aires-Facultad de Ciencias Sociales/Université de Tours-École Doctorale Sciences de l'Homme et de la Société.

Schteingart, Martha (1987), "Expansión urbana, conflictos sociales y deterioro ambiental en la ciudad de México. El caso del Ajusco", Estudios demográficos y urbanos, 2 (3), Ciudad de México, El Colegio de México, pp. 449-477.

Sieder, Rachel; Schjolden, Line y Angell, Alan (2008), La judicialización de la política en América Latina, Bogotá, Universidad Externado de Colombia.

Svampa, Maristella y Viale, Enrique (2014), Maldesarrollo. La Argentina del extractivismo y el despojo, Buenos Aires, Katz Editores.

Svampa, Maristella; Bottaro, Laura y Sola Álvarez, María (2009), "La problemática de la minería metalífera a cielo abierto: modelo de desarrollo, territorio y discursos dominantes", en Maristella Svampa y Mirta Antonelli (eds.) Minería transnacional, narrativas del desarrollo y resistencias sociales, Buenos Aires, Biblos, pp. 29-50.

Thomas, William y Thomas, Dorothy (1928), The child in America. Behaviour problems and programs, New York, Alfred A. Knopf.

Vallejos-Romero, Arturo (2008), "Conflictos socioambientales en la periferia de la modernidad: apuntes para la intervención en contextos locales", Revista de Ciencias Sociales, 14 (2), Maracaibo, Universidad del Zulia, pp. 240-254.

Weber, Max (2012), Ensayos sobre metodología sociológica, Buenos Aires, Amorrortu.

Recibido: 29 de octubre de 2019. Reenviado: 20 de febrero de 2020. Aceptado: 10 de marzo de 2020.

Andrés Scharager. Doctor en Ciencias Sociales por la Universidad de Buenos Aires y en Geografía por la Université de Tours. Actualmente es docente de Teoría Sociológica en la Facultad de Ciencias Sociales en la carrera de Sociología de la Universidad de Buenos Aires y becario posdoctoral del Consejo Nacional de Investigaciones Científicas y Técnicas (Conicet), Argentina, con sede en el Instituto de Altos Estudios Sociales de la Universidad Nacional de San Martín (IDAES-UNSAM). Sus líneas de 
investigación se centran en el campo de la sociología política, en la intersección entre los procesos políticos, la justicia y el conflicto. Entre sus últimas publicaciones destacan, como autor, "De cómo una resolución judicial se convierte en un problema político y social. La relocalización de villas en la cuenca Matanza-Riachuelo", Quid, 16 (12), Caba, Universidad de Buenos Aires (UBA) y Facultad de Ciencias Sociales, pp. 359-363 (2019); “Más allá del lawfare: avatares de la judicialización de las políticas públicas y los conflictos sociales en Argentina y América Latina", Direito da Cidade, 12 (1), Rio de Janeiro, Universidade do Estado do Rio de Janeiro, pp. 280-305 (2020); en coautoría, "Les territoires du droit de l'environnement: effets de la judiciarisation dans le bassin Matanza-Riachuelo (Buenos Aires)", Annales de Géographie (próximamente). 